\title{
West Indian Drywood Termite Cryptotermes brevis (Walker) (Insecta: Isoptera: Kalotermitidae) ${ }^{1}$
}

\author{
Johnalyn M. Gordon, Rudolf H. Scheffrahn, and Nan-Yao Su²
}

The Featured Creatures collection provides in-depth profiles of insects, nematodes, arachnids, and other organisms relevant to Florida. These profiles are intended for the use of interested laypersons with some knowledge of biology as well as academic audiences.

\section{Introduction}

Cryptotermes brevis (Walker), commonly known as the West Indian drywood termite, is an important pest species throughout tropical and some subtropical regions around the world (Scheffrahn et al. 2009) with the exception of Asia (Scheffrahn et al. 2008), where Cryptotermes cynocephalus Light, Cryptotermes domesticus (Haviland), and Cryptotermes dudleyi Banks are more prevalent (Krishna et al. 2013). Cryptotermes brevis is known to colonize moisture-protected wood in service, including houses, boats, furniture, etc. Their propensity to infest wooden articles, along with their relatively low moisture needs, have resulted in the ease of transport and eventual introduction of these termites via anthropogenic means (Scheffrahn and $\mathrm{Su}$ 1990). From there, further introduction events have allowed this species to spread throughout the US Gulf Coast, especially southern Florida, where they have become the preeminent drywood pest of wooden articles. This species' status as a structural pest distinguishes it from a native but related species, Cryptotermes cavifrons Banks, which rarely poses a threat to buildings as it prefers an outdoor, forest habitat, due to its requirement of occasional exposure to rainfall.

\section{Distribution}

Until recently, the native range of the West Indian drywood termite was unknown. The common name refers to the area where the type specimens were collected-in Jamaica in 1845 and later throughout the West Indies (Walker 1853). It has since been determined that Cryptotermes brevis is endemic to the coastal desert of Peru and Chile (Scheffrahn et al. 2009). The Spanish conquistadors who made landfall along this coast were likely responsible for spreading Cryptotermes brevis by sailing infested ships and goods from the termites' isolated coastal habitat to other parts of the New World (Scheffrahn et al. 2008). The current US distribution, in order of establishment, includes Florida, Hawaii, Puerto Rico, US Virgin Islands, and the southeastern Gulf Coast (Figure 1). The species was first recorded in Florida in 1918 from a structure in Key West (Scheffrahn et al. 1988) and has since spread throughout coastal regions of the state (Figure 2). The largest populations have been found in older buildings in the southern half of Florida (Scheffrahn et al. 1988).

1. This document is EENY-79, one of a series of the Entomology and Nematology Department, UF/IFAS Extension. Original publication date April 1999. Revised January 2005 and September 2020. Visit the EDIS website at https://edis.ifas.ufl.edu for the currently supported version of this publication. This document is also available on the Featured Creatures website at http://entomology.ifas.ufl.edu/creatures.

2. Johnalyn M. Gordon; Rudolf H. Scheffrahn, professor of entomology, UF/IFAS Fort Lauderdale Research and Education Center; and Nan-Yao Su, distinguished professor, entomology, UF/IFAS Fort Lauderdale REC; UF/IFAS Extension, Gainesville, FL 32611.

The Institute of Food and Agricultural Sciences (IFAS) is an Equal Opportunity Institution authorized to provide research, educational information and other services

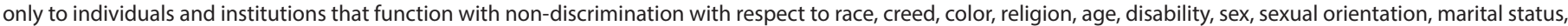

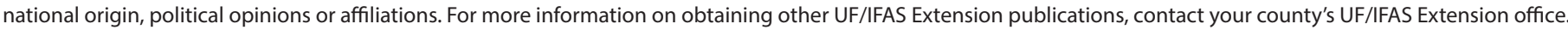
U.S. Department of Agriculture, UF/IFAS Extension Service, University of Florida, IFAS, Florida A \& M University Cooperative Extension Program, and Boards of County Commissioners Cooperating. Nick T. Place, dean for UF/IFAS Extension. 


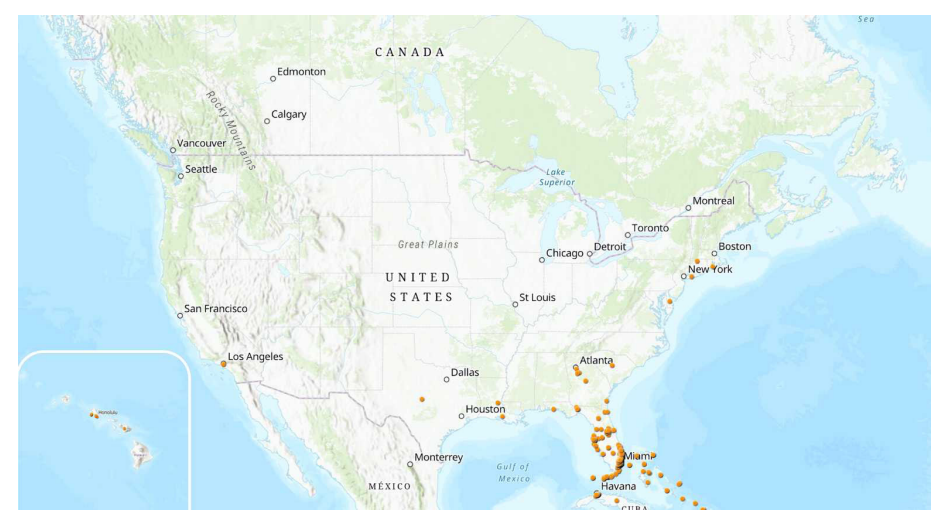

Figure 1. 2017 US distribution of Cryptotermes brevis (Walker). Credits: Map by Johnalyn M. Gordon, UF/IFAS; locality data are from the University of Florida Termite Collection, available at termitediversity.org

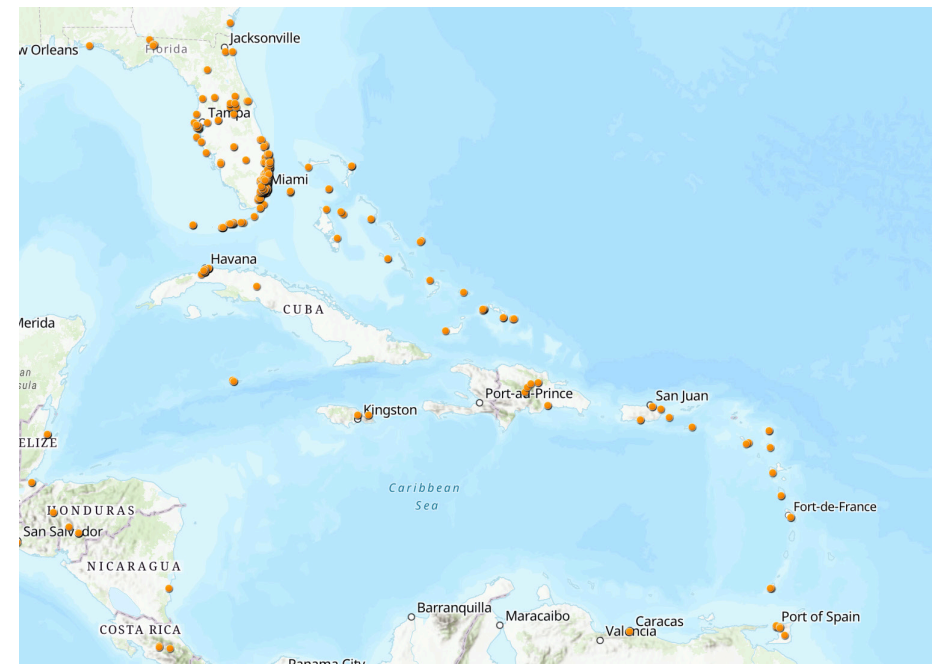

Figure 2. 2017 distribution of Cryptotermes brevis (Walker) in Florida and the Caribbean.

Credits: Map by Johnalyn M. Gordon, UF/IFAS; locality data are from the University of Florida Termite Collection, available at termitediversity.org

\section{Description and Identification}

Like other termites, Cryptotermes brevis is a social insect that possesses chewing mouthparts, moniliform (beadlike) antennae, well-developed tarsal claws that provide grip on wood, and all castes (see below), except reproductives, lack eyes. When compared to subterranean termites, drywood termites also tend to have larger, more cylindrical bodies, with shorter legs that result in much slower movement.

Drywood termites have several castes within their colonies (Figures 3 and 4): reproductives (fertile kings and queens living in the nest) and, periodically, alates (winged reproductives) (Figure 5) that fly from the nest to establish new colonies and can be distinguished from other castes by their comparatively darker body color (Figure 6), pseudergates ("false workers"), soldiers, larvae, and eggs. Soldiers and alates are most reliably used for identification purposes. Soldiers possess characteristic dark and rugose head capsules (Figure 7) and the pronotum of drywood termite soldiers is always as wide as or wider than the head. Alates possess two easily identifiable pairs of hairless, but vividly iridescent wings (Figures 8 and 9), which have three to four darkened and pronounced veins within the costal margin, these being the radius and radial sector. Cryptotermes brevis can also be differentiated from other drywood termites in this genus by its lack of an arolium, a rounded, pad-like structure located between the tarsal claws, which is present in other Cryptotermes species but is noticeably absent in Cryptotermes brevis (Figure 10).

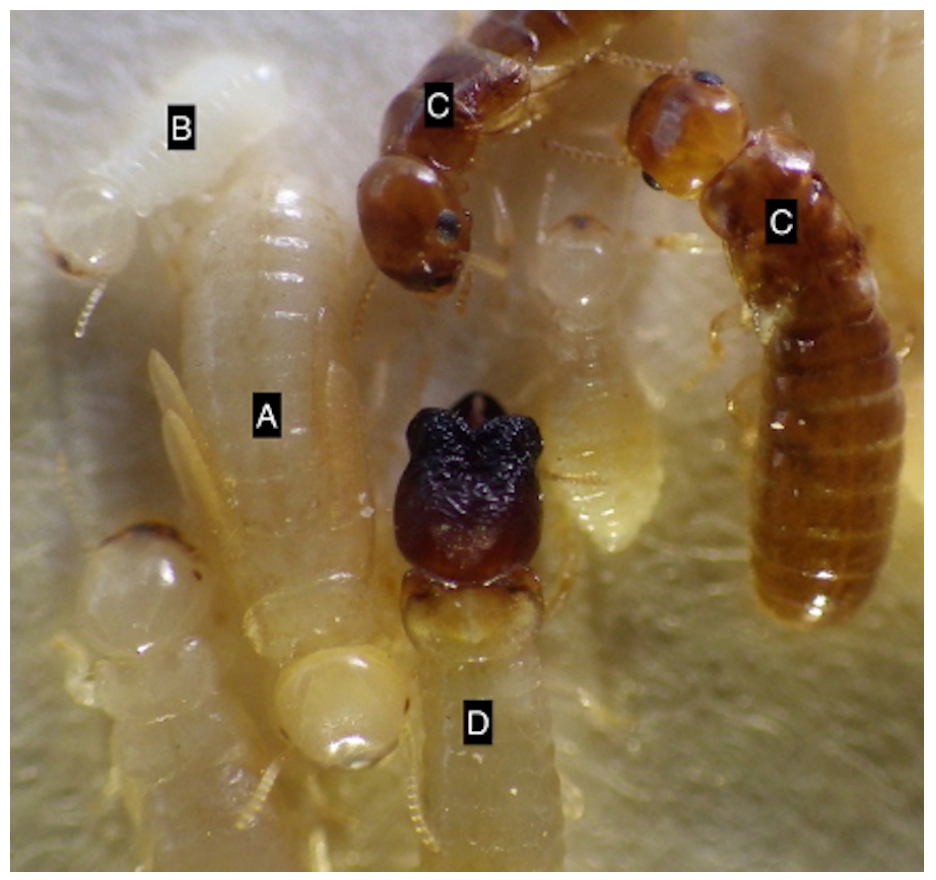

Figure 3. Cryptotermes brevis (Walker) pseudergate (A), nymph (B), dealates (C), and soldier (D).

Credits: Johnalyn M. Gordon (johnalynmgordon@ufl.edu), University of Florida

\section{Life Cycle and Biology}

Drywood termites differ from subterranean termites in that the colony lives entirely within wood. Despite this lack of contact with soil, drywood termites are capable of deriving moisture both from water bound to wood they feed on and as a product of their own metabolic processes. Annually, before the rainy season in early spring, a portion of the pseudergate population in mature colonies molts into alates. These alates leave the colony on multiple mating flights from April to June, though flights are possible any time of the year. After flight, alates shed their wings (then referred to as "dealates"), and a single male and female will pair off to perform a behavior known as "tandeming" in which the male follows the female closely as they seek out a suitable location, such as a crack, hole, or knot in a wooden surface, to start their colony (Minnick 1973). They then 


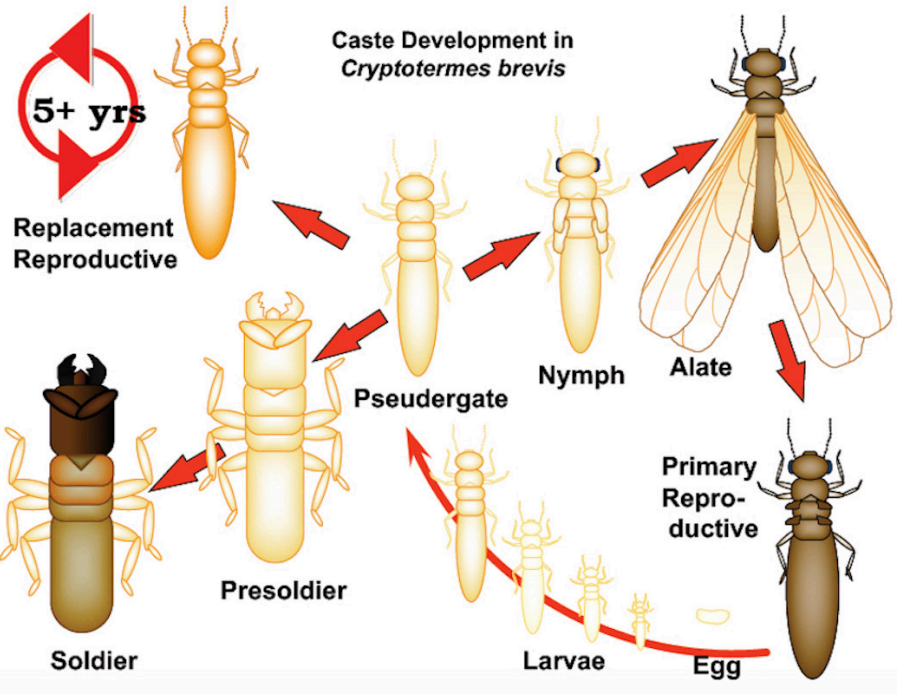

Figure 4. Caste development in Cryptotermes brevis (Walker). Credits: Original figure by Rudolf H. Scheffrahn (rhsc@ufl.edu), UF/ IFAS. Edited by Johnalyn M. Gordon (johnalynmgordon@ufl.edu), University of Florida

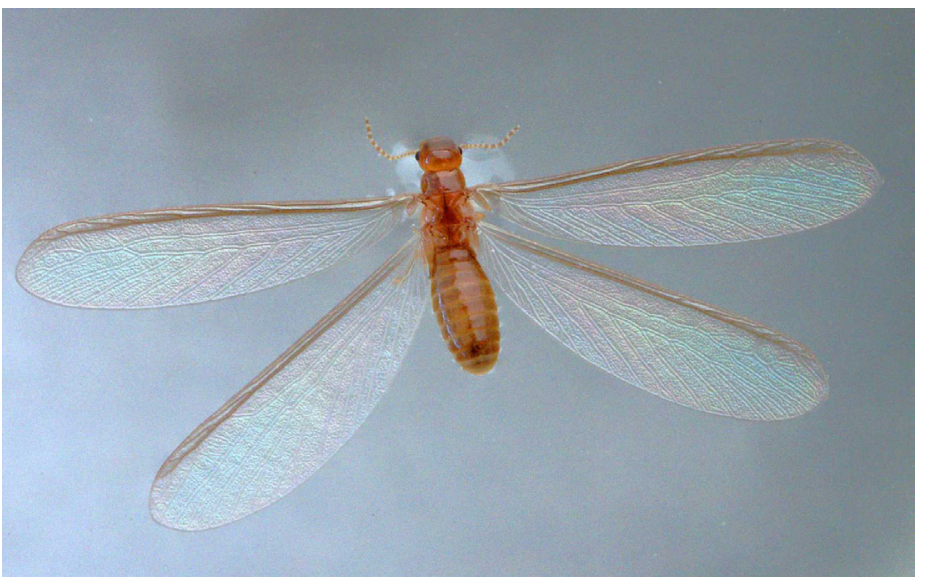

Figure 5. Cryptotermes brevis (Walker) alate on water. Credits: Rudolf H. Scheffrahn (rhsc@ufl.edu), UF/IFAS

excavate this area further to form the nuptial chamber, in which they mate and the female begins laying eggs. Two to three years after the colony's inception, soldiers begin to appear. Alates are not produced until the colony is mature, at approximately five years of age, and are present for the rest of the life of the colony, which can exceed ten years.

\section{Economic Importance}

Cryptotermes brevis is solely associated with man-made structures, having never been found in a natural habitat outside of coastal Peru and Chile (Scheffrahn et al. 2001; Scheffrahn et al. 2008). Since their introduction into the United States, they have become an economically important pest species. Nearly all structural fumigation in Florida and Hawaii is for Cryptotermes brevis control. This accounts for approximately $\$ 140$ and $\$ 30$ million worth in treatment costs, respectively, caused by this species annually in those states (Scheffrahn, unpublished data).

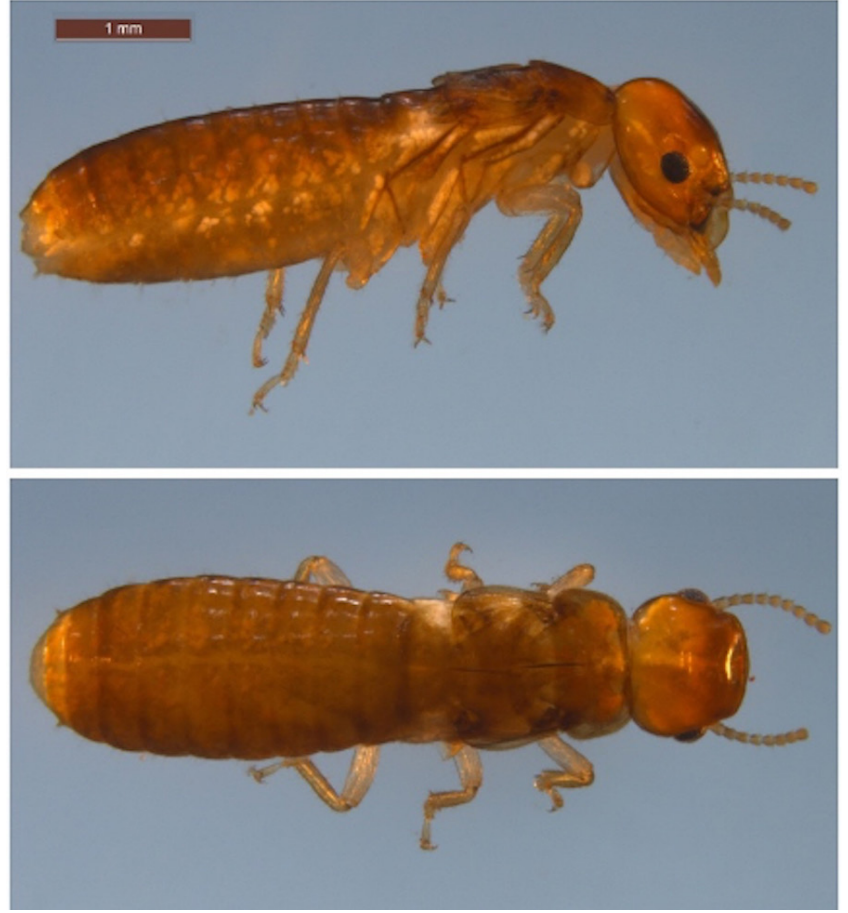

Figure 6. Cryptotermes brevis (Walker) dealate (post-flight imago), lateral (top) and dorsal (bottom) views.

Credits: Johnalyn M. Gordon (johnalynmgordon@ufl.edu), UF/IFAS

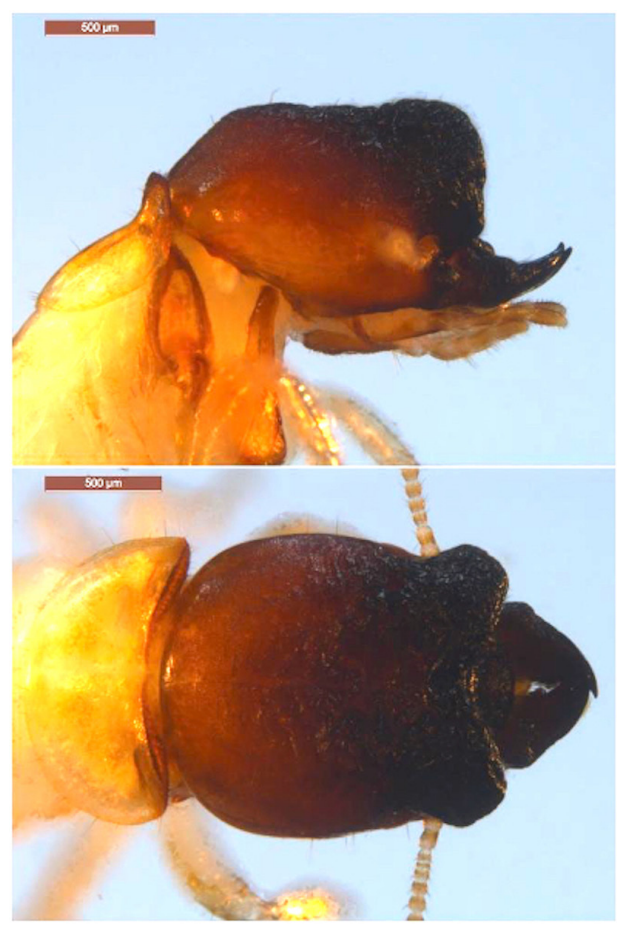

Figure 7. Cryptotermes brevis (Walker) soldier head, lateral (top) and dorsal (bottom) views.

Credits: Johnalyn M. Gordon (johnalynmgordon@ufl.edu), UF/IFAS

\section{Damage}

Drywood termites tend to be more common in older metropolitan areas, with aged wooden structures and high population density, though they can infest new wood as well. Colonies have been known to infest hardwoods 


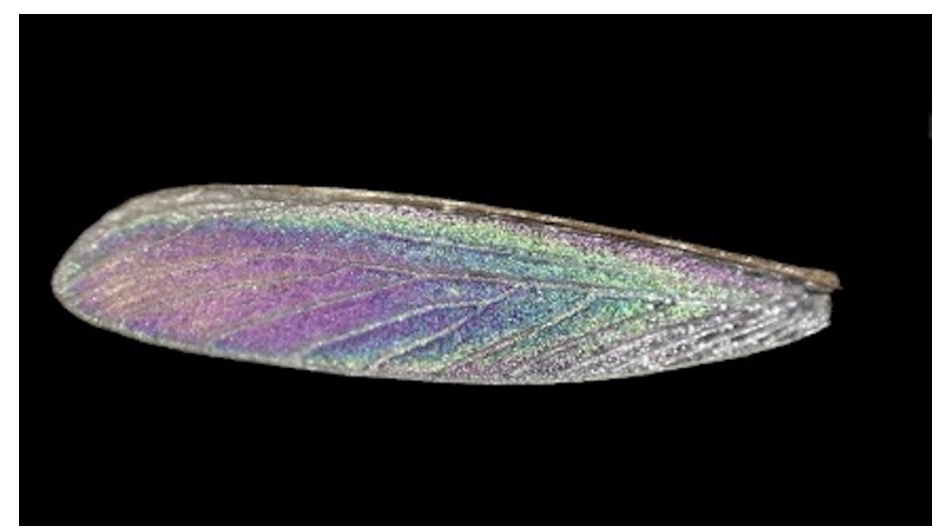

Figure 8. Cryptotermes brevis (Walker) wing with characteristic striking iridescence.

Credits: Johnalyn M. Gordon (johnalynmgordon@ufl.edu), UF/IFAS

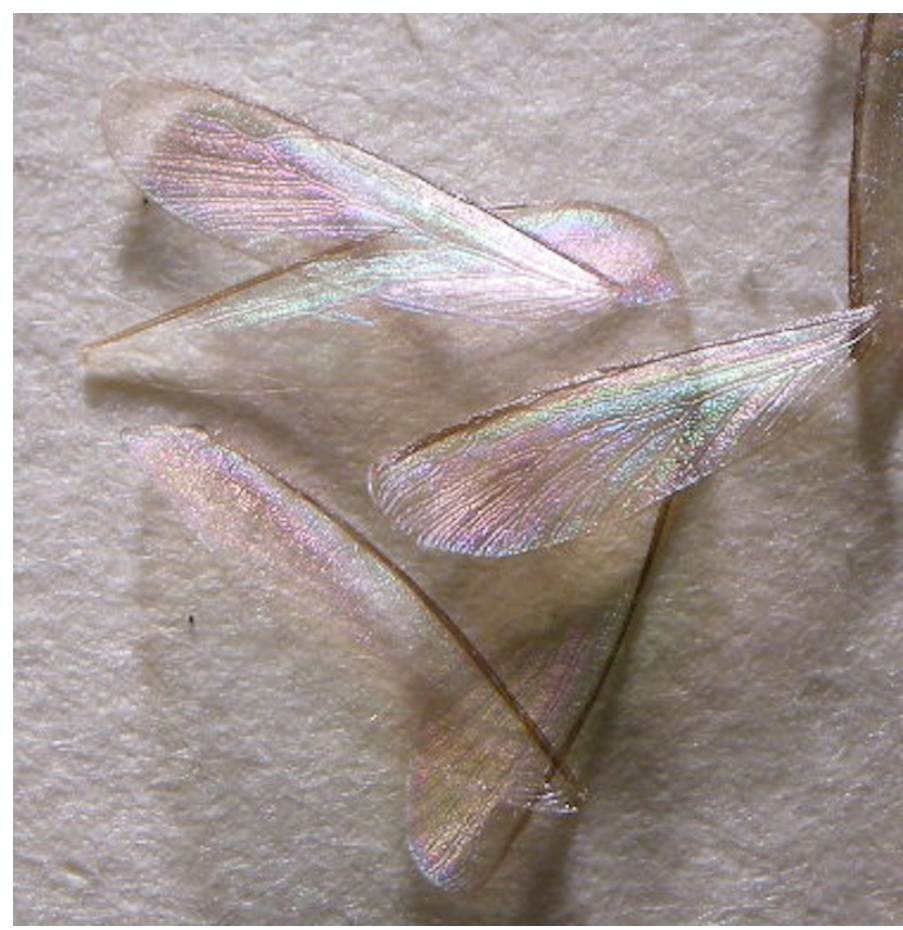

Figure 9. Cryptotermes brevis (Walker) wings.

Credits: Rudolf H. Scheffrahn (rhsc@ufl.edu), UF/IFAS

and softwoods that are shielded from rainfall, including common lumber used in building, as well as furniture. Drywood termites appear to have preference for sapwood and excavate galleries within (Scheffrahn, personal observation) (Figure 11). Infestations typically remain within the wood, but external signs of infestation may be the blistering or peeling of thin surface wood or paint, as well as the presence of feces, commonly referred to as fecal pellets, which pseudergates push out of "kick-out" holes (usually 1 to $2 \mathrm{~mm}$ in diameter) (Figure 12). Fecal pellets often accumulate in piles (Figure 13) or scatter circles, depending on the height of the hole from the ground (Scheffrahn and Su 1990). Drywood termite pellets are hexagonal in cross section (Figure 14) and can be a variety of colors, including
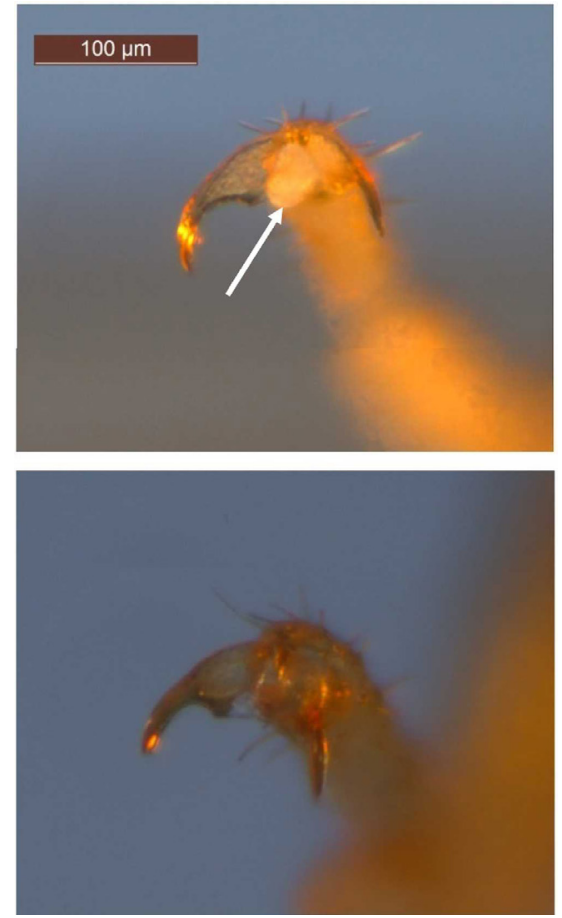

Figure 10. Comparison of arolium structure in two Cryptotermes species. Cryptotermes cavifrons (Banks), top, with arolium between tarsal claws indicated by arrow and Cryptotermes brevis (Walker), bottom, without arolium.

Credits: Johnalyn M. Gordon (johnalynmgordon@ufl.edu), UF/IFAS

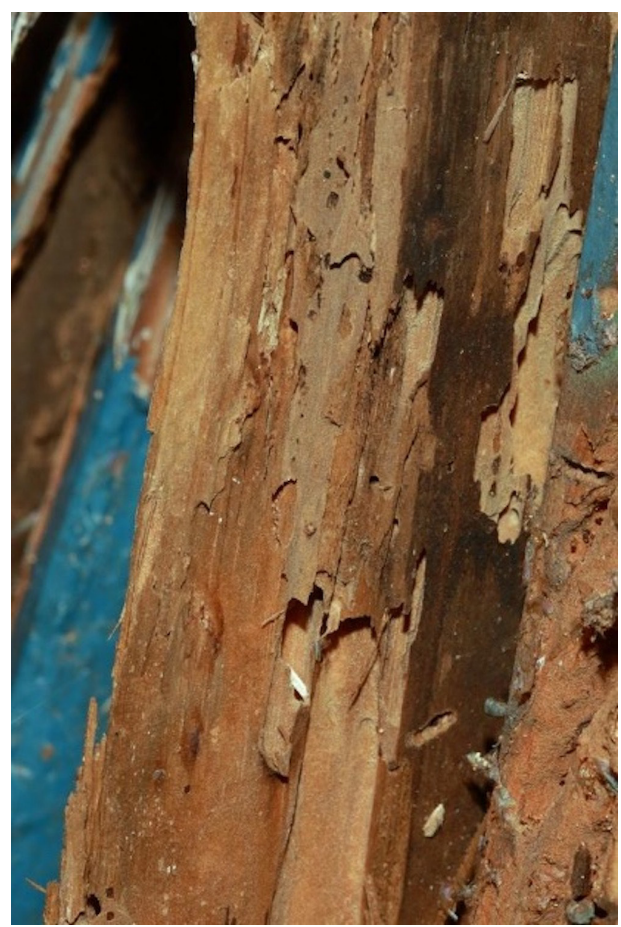

Figure 11. Wood damaged by Cryptotermes brevis (Walker). Credits: Johnalyn M. Gordon, UF/IFAS

cream, red, or black (Figures 13, 14, and 15). It is unknown what determines pellet color, as color is unaffected by temporal changes or the color of the wood the termites are feeding on. 


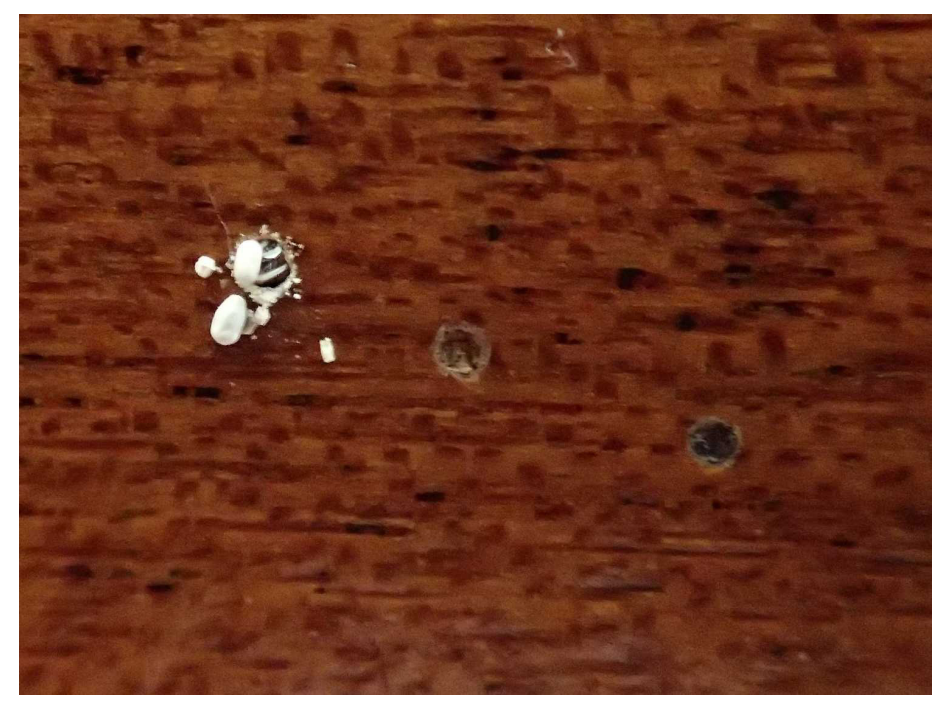

Figure 12. Open (right) and closed (middle and left) kick-out holes from Cryptotermes brevis (Walker), approximately 1 to $2 \mathrm{~mm}$ in diameter.

Credits: Rudolf H. Scheffrahn (rhsc@ufl.edu), UF/IFAS

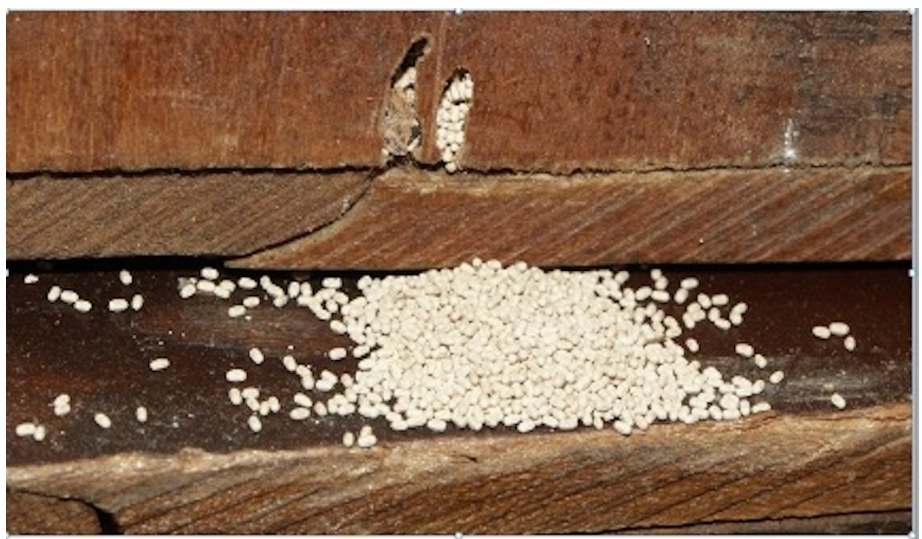

Figure 13. Pile of fecal pellets from Cryptotermes brevis (Walker). Credits: Rudolf H. Scheffrahn (rhsc@ufl.edu), UF/IFAS

\section{Management}

Conducting a visual search to identify drywood termite colonies within a structure can be very difficult, due to the need to search in difficult-to-reach or inaccessible areas, such as narrow crawlspaces and inside of walls. In addition to visual inspection, other methods of detection have been used. These include, but are not limited to, the probing of wood with a metal probe, termite detection dogs (Brooks et al. 2003), infrared cameras, portable x-ray machines, and acoustic detection methods (Lewis et al. 2009). Each of these methods have been used with varying levels of success but are often hampered by cost and the difficulty of use of the treatment method itself (Lewis and Forschler 2014). Additionally, accessibility remains a challenge with all of these detection methods.

There are two main methods of drywood termite control: 1) alate prevention, which can include exclusion,

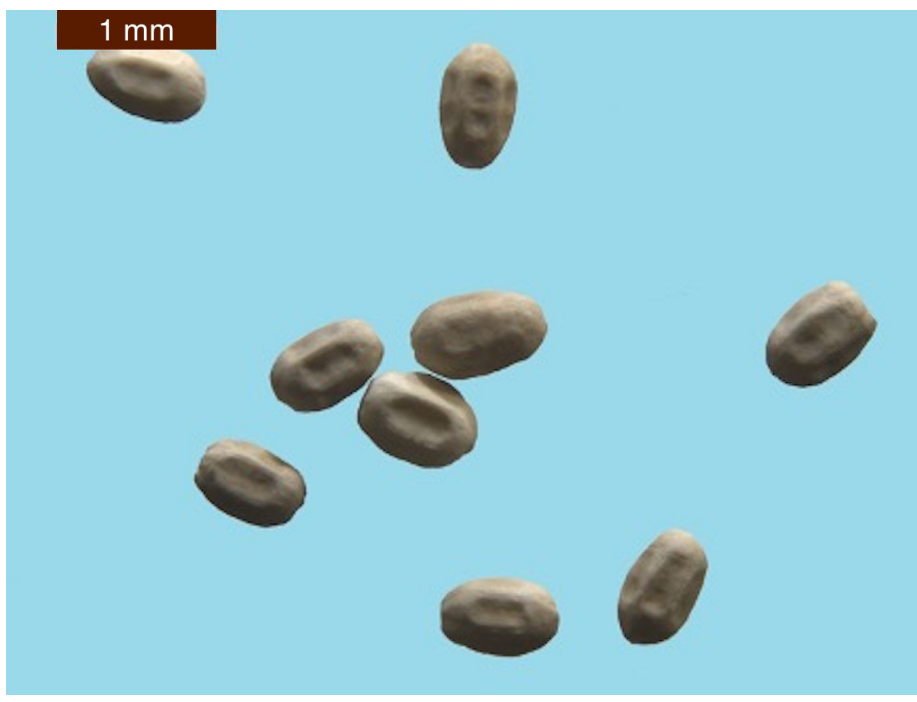

Figure 14. Pellets of Cryptotermes brevis (Walker).

Credits: Johnalyn M. Gordon (johnalynmgordon@ufl.edu), UF/IFAS

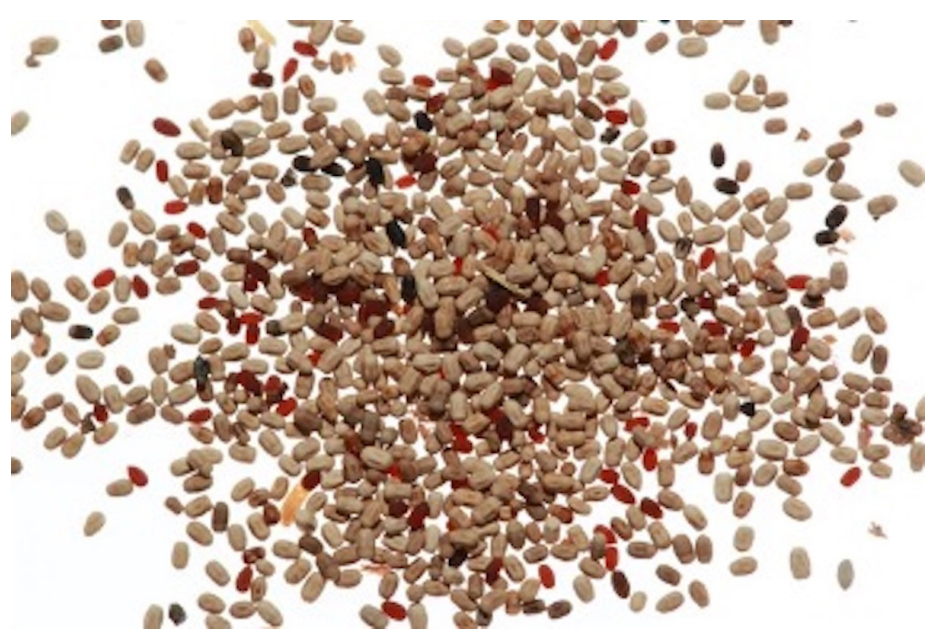

Figure 15. Color variation in Cryptotermes brevis (Walker) fecal pellets. Credits: Johnalyn M. Gordon (johnalynmgordon@ufl.edu), UF/IFAS

wood-surface treatment, and use of preserved wood, and 2) spot treatment or fumigation.

Exclusion of alates includes the application of caulk or small mesh screening (with holes smaller than alate head width, approximately $1 \mathrm{~mm}$ ) to prohibit entry of alates through openings in the structure. However, despite these "tight" building practices, complete exclusion is almost impossible. Additional treatment of susceptible areas within a structure, such as attics and wall voids, with toxic or desiccating dusts such as borax dust, can be attempted as a preventative treatment to kill alates before they are able to construct nuptial chambers and start a colony. Application of other preventative chemicals to treat the structure may occur during the framing phase of building when all wood can be easily treated. The use of pressure-treated wood (treated with chromated copper arsenate, often abbreviated as CCA) is known to deter colonization by termites (Scheffrahn et al. 1998; Scheffrahn and Su 1990). However, the 
use of CCA-treated wood in residential structures has been largely restricted since 2003 in an effort to protect human health and the environment from exposure to the arsenic in CCA-treated wood (U.S. Environmental Protection Agency [EPA] 2017). CCA-treated wood is still used in some structures.

In the event of inaccessible or widespread infestation of a structure, the primary method of control is fumigation (Scheffrahn and Su 1990), which involves "tenting" the structure with gas-tight tarpaulins and releasing sulfuryl fluoride (Scheffrahn and Su 1990), followed by aeration to 1 ppm or less (Lewis and Haverty 1996; Scheffrahn et al. 1997). Thermal treatments are also used, but due to technical and economic constraints, are normally not implemented for whole-house treatments, and instead are classified as compartmental treatments. Heat is administered using propane or electric heaters (Lewis and Haverty 1996) and is typically used on single rooms within a structure, like a single bedroom, or on single apartments in multi-family complexes.

Localized, or "spot," treatments are also a common treatment method. For in-wood injections, or "drill-and-treat" applications, holes are drilled into the infested wood and insecticide is injected inside hollow galleries formed by the termites. Products can also be injected into the kick-out holes, if they can be located. Often paired with drill-andtreat control are the spray or foam applications of borate solutions or other insecticides to susceptible raw wood surfaces, as possible preventative measures. Additional, less commonly used methods of localized treatment include the use of microwave energy to kill termites through heat in smaller areas of wood, electrocution via a handheld high-energy, low-current "gun" and the complete removal of infested wood in isolated wood structures, such as a door (Lewis and Haverty 1996).

It is often difficult to determine the success of a drywood termite treatment, as colonies are hidden inside of the infested wood. Pellet production and alate flights can indicate the presence of Cryptotermes brevis in the structure (Figures 12, 13, and 16), so the removal of all pellets and wings after a treatment provides a good monitoring system. After a treatment that has been accompanied by these removal measures, any new and growing piles of pellets and/or presence of alates or wings, typically indicate that the treatment was unsuccessful. However, it is important to note that remaining fecal pellets may be dislodged from previously-infested wood if disturbed by movement or vibrations, so the presence of those may not always indicate an active colony.

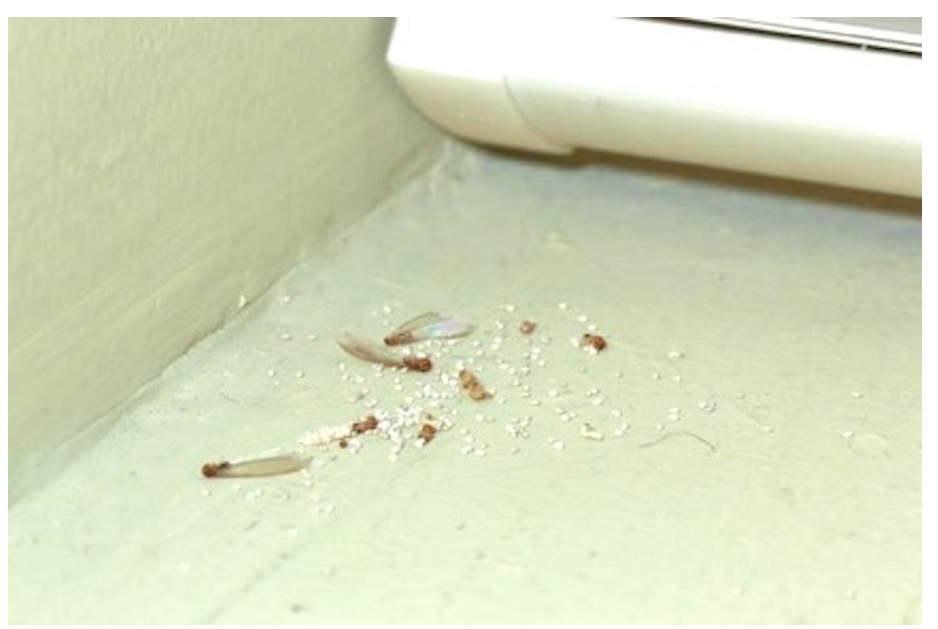

Figure 16. Cryptotermes brevis (Walker) imagos and fecal pellets on windowsill.

Credits: Johnalyn Gordon, UF/IFAS

\section{Selected References}

Bacchus S. 1987. "A taxonomic and biometric study of the genus Cryptotermes (Isoptera: Kalotermitidae)." Tropical Pest Bulletin 7:1-91.

Edwards R, Mill AE. 1986. Termites in buildings, their biology and control. Rentokil Limited, East Grinstead.

Haverty MI, Woodrow RJ, Nelson LJ, Grace JK. 2005. "Identification of termite species by the hydrocarbons in their feces." Journal of Chemical Ecology 31:2119-2125. https://doi.org/10.1007/s10886-005-6081-8

Krishna K, Grimaldi DA, Krishna V, Engel MS. “Treatise on the Isoptera of the World." Bulletin of the American Museum of Natural History No. 377, American Museum of Natural History, New York, NY. https://doi. $\operatorname{org} / 10.1206 / 377.6$

Lewis VR, Haverty MI. 1996. "Evaluation of six techniques for control of the western drywood termite (Isoptera: Kalotermitidae) in structures." Journal of Economic Entomology 89:922-934. https://doi.org/10.1093/jee/89.4.922

Lewis VR, Moore S, Rabuchi R, Getty G. 2009. “Field evaluations of localized treatments for the control of drywood termite infestations in California." Final Report to the California Structural Pest Control Board, Sacramento, California, USA, pp. 1-28. http://www.pestboard.ca.gov/ howdoi/research/2009_field_rpt.pdf

Lewis VR, Forschler BT. 2014. "Management of Drywood Termites: Past Practices, Present Situation, and Future Prospects." In Urban Insect Pests: Sustainable Management Strategies (Partho Dhang). Oxfordshire, UK: CABI. 
Minnick DR. 1973. "The flight and courtship behavior of the drywood termite, Cryptotermes brevis." Environmental Entomology 2:587-92. https://doi.org/10.1093/ee/2.4.587

Scheffrahn RH, Busey P, Edwards JK, Křeček J, Maharajh B, Su N-Y. 2001. "Chemical prevention of colony foundation by Cryptotermes brevis (Isoptera: Kalotermitidae) in attic modules." Journal of Economic Entomology 94:915-919. https://doi.org/10.1603/0022-0493-94.4.915

Scheffrahn RH, Křeček J, Ripa R, Luppichini, P. 2008. "Endemic origin and vast anthropogenic dispersal of the West Indian drywood termite." Biological Invasions 11:787-799. https://doi.org/10.1007/s10530-008-9293-3

Scheffrahn RH, Mangold JR, Su N-Y. 1988. "A survey of structure-infesting termites of peninsular Florida." Florida Entomologist 71:615-630. https://doi.org/10.2307/3495021

Scheffrahn RH, Su N-Y. 1990. "Economically important termites in the United States and their control." Sociobiology 17 (1): 77-94.

Scheffrahn RH, Su N-Y, Busey P. 1997. "Laboratory and field evaluations of selected chemical treatments for control of drywood termites (Isoptera: Kalotermitidae)." Journal of Economic Entomology 90:492-502. https://doi.org/10.1093/ jee/90.2.492

Scheffrahn RH, Su N-Y, Křčcek J, Van Liempt A, Maharajh B, Wheeler GS. 1998. "Prevention of colony foundation by the drywood termite, Cryptotermes brevis, and remedial control of drywood termites (Isoptera: Kalotermitidae) with selected chemical treatments." Journal of Economic Entomology 91:1387-1396. https://doi.org/10.1093/jee/91.6.1387

U.S. Environmental Protection Agency [EPA]. Chromated Arsenicals (CCA). (2016, November 22). Retrieved August 24, 2017, from https://www. epa.gov/ingredients-used-pesticide-products/ chromated-arsenicals-cca

Walker F. 1853. "List of the specimens of neuropterous insects in the collection of the British Museum. Part III (Termitidae-Ephemeridae)." London: Trustees of the British Museum 4:477-585. 